the $C$-terminal residue, indicating that the bond between humic acid and the $N$-terminal glycine residue is more stable to hydrolysis than is the peptide bond. These observations support the suggestions of workers using model systems involving the reaction of amino acids and phenols undergoing oxidation. It therefore could well be that at least a proportion of the stable amino nitrogen in humic acid is bound by $N$-phenyl linkages, as suggested by Flaig (1966).

D. R. P. acknowledges the support of a Science Research Council Research Studentship.

Ball, D. F. (1960). Mem. Soil Surv. Gt Br. London: HMSO. Bremner, J. M. (1955). J. agric. Sci. 46, 247.

Flaig, W. (1966). Rap. F.A.O./I.A.E.A. Tech. Meet. Brunswick, Volkenrode, 103-127.

Haider, K., Frederick, L. R. \& Flaig, W. (1965). Pl. Soil, 22, 49.

Ladd, J. N. \& Butler, J. H. A. (1966). Aust. J. Soil Res. 4,41 .

\section{Effect of Gibberellic Acid on the Development of some Cereal Carbohydrases}

By D. J. Manners, G. H. Palmer, G. Wilson and D. Yellowleses. (Department of Brewing and Biological Sciences, Heriot-Watt University, Edinburgh $E H 11 H X, U . K .$, and the Brewing Industry Research Foundation, Nutfield, Redhill, Surrey RH1 $4 H Y, U . K$.

Although it is generally accepted that gibberellic acid stimulates the production of $\alpha$-amylase by the aleurone layer of the barley endosperm (MacLeod, 1967), the effect of this hormone on the development of other carbohydrases is not so well established. For example, although MacLeod \& Millar (1962) and MacLeod, Duffus \& Johnston (1964) have sug. gested that the formation of endo- $\beta$-glucanase is substantially increased by gibberellic acid, a recent report by Bourne \& Pierce (1970) does not support this view.

Extracts of malted barley contain at least two $\beta$-glucosidases, three endo- $\beta$-glucanases and a limit dextrinase (Manners \& Marshall, 1969; Manners, Marshall \& Yellowlees, 1970). Since all of these enzymes may be involved either directly or indirectly in the utilization of the carbohydrate reserves of barley, we now describe the effect of gibberellic acid on their development.

Barley (var. Proctor) was malted on a pilot scale, by using the following procedure. The grain was steeped in water for $8 \mathrm{~h}$, followed by an air rest $(24 \mathrm{~h})$ and a further steep for $24 \mathrm{~h}$ in either gibberellic acid solution (0.5p.p.m.) or water. The grain was allowed to germinate at $16^{\circ} \mathrm{C}$ for 5 days, samples being removed every day, and then air-dried at $90.5^{\circ} \mathrm{C}\left(195^{\circ} \mathrm{F}\right)$. Samples of barley (500 grains) were taken, weighed and ground. Protein was then extracted from the flour as described by Manners \& Marshall (1969).

The activity of the extracts towards laminaribiose and cellobiose varied during the 5 days of germination, but there was no significant difference between the gibberellic acid-treated and control samples. The endo- $\beta-(1 \rightarrow 4)$-glucanase activity, assayed viscometrically against sodium carboxymethylcellulose, was also unaffected by gibberellic acid. However, there was a significant increase in the rate of development of both endo- $\beta$-glucanase activity towards barley $\beta$-glucan and endo- $\beta$ - $(1 \rightarrow 3)$ glucanase activity that was stimulated by gibberellic acid. When assayed viscometrically against barley $\beta$-glucan, the activity during a germination time of 4 days increased from 0.03 to 0.13 unit in the control, and from 0.03 to 0.27 units after gibberellic acid treatment. With sodium carboxymethylpachyman as substrate the activities increased from 0.13 to 0.17 unit and from 0.13 to 0.41 unit respectively.

Assays for limit dextrinase activity were also carried out with pullulan as the substrate (Manners \& Yellowlees, 1970). There were 10-fold and 15-fold increases between the first and fourth days of germination in the control and in the gibberellic acid-treated barley. These results were also confirmed when samples of abraded barley (Palmer, 1969) were steeped in either water or gibberellic acid and then malted. Again there was a significant stimulation of the production of limit dextrinase by gibberellic acid.

The present results suggest that there is not a common mode for the production of cereal carbohydrase activity. It seems likely that some of these enzymes [ $\alpha$-amylase, limit dextrinase, endo- $\beta$ $(1 \rightarrow 3)$-glucanase, endo- $\beta$-glucanase activity to. wards barley $\beta$-glucan] are produced in the aleurone cells by a mechanism that is sensitive to exogenous gibberellic acid. However, it is now clear that other carbohydrases [laminaribiase, cellobiase, endo- $\beta$-( $1 \rightarrow 4)$-glucanase] are produced by a pathway that is not affected by exogenous gibberellic acid. The biochemical explanation for this difference remains for future investigations.

We thank Dr A. H. Cook, F.R.S., for his interest in this work, which was sponsored by the Brewing Industry Research Foundation, and the Science Research Council for a research studentship (to G. W.).

Bourne, D. T. \& Pierce, J. S. (1970). J. Inst. Brew. 76, 328. MacLeod, A. M. (1967). Wallerstein Lab. Commun. 30, 85. MacLeod, A. M., Duffus, J. H. \& Johnston, C. S. (1964). J. Inst. Brew. 70, 521.

MacLeod, A. M. \& Millar, A. H. (1962). J. Inst. Brew. 68, 322. 
Manners, D. J. \& Marshall, J. J. (1969). J. Inst. Brew. 75, 550 .

Manners, D. J., Marshall, J. J. \& Yellowlees, D. (1970). Biochem. J. 116, 539.

Manners, D. J. \& Yellowlees, D. (1970). Biochem. J. 117, $22 P$.

Palmer, G. H. (1969). J. Inst. Brew. 75, 536.

\section{Observations on the Purity of some Yeast Glycogen Preparations}

By R. B. Evans and D. J. Manners. (Department of Brewing and Biological Sciences, Heriot-Watt University, Edinburgh EH1 $1 H X, U . K$.

Recent investigations by Bacon and his coworkers (Bacon \& Farmer, 1968; Bacon, Farmer, Jones \& Taylor, 1969) and by Manners \& Masson (1969) have shown that yeast cell-wall preparations contain a soluble $\beta$ - $(1 \rightarrow 6)$-glucan in addition to the branched insoluble $\beta$-(1 $\rightarrow 3)$-glucan. A survey of the literature shows a considerable variation in the specific rotation and $\beta$-amylolysis limits of various yeast glycogen preparations, and this is rather surprising in view of the generally accepted molecular structure of the polysaccharide (Manners, 1957). It is possible that this variation could be due, in part, to contamination of the glycogen preparations to differing extents with $\beta$-(1 $1 \rightarrow 6)$-glucan, and we now describe experimental evidence to support this suggestion.

Baker's yeast was fractionated by the method of Trevelyan \& Harrison (1956) to give the following fractions: trehalose, mannan and alkali-soluble glycogen, acetic acid-soluble glycogen, perchloric acid-soluble glycogen and residual $\beta$-(1 $\rightarrow 3)$-glucan. The glycogen samples were then deproteinized by treatment with ice-cold $5 \%$ trichloroacetic acid solution.

Samples of the acetic acid-soluble glycogen and perchloric acid-soluble glycogen were partially hydrolysed $\left(0.167 \mathrm{M}\right.$-sulphuric acid at $100^{\circ} \mathrm{C}$ for $30 \mathrm{~min}$ ). Paper chromatography showed the presence of glucose and maltosaccharides (degree of polymerization 2-5), but no other oligosaccharides. However, when the conditions for partial hydrolysis were altered to those that would be suitable for the $\beta$-(1 $1 \rightarrow 6)$-glucan luteose, i.e. $1 \mathrm{M}$-sulphuric acid at $100^{\circ} \mathrm{C}$ for $1 \mathrm{~h}$, the partial hydrolysates con. tained glucose and oligosaccharides with the chromatographic mobility of gentiobiose and gentiotriose.

The yeast glycogens were then treated with a purified amyloglucosidase preparation, which had no action on luteose but with rabbit liver glycogen gave $98.4 \%$ conversion into glucose. By using both glucose oxidase and Nelson-Somogyi reducingpower methods of analysis, the acetic acid-soluble glycogen gave 78 and $79 \%$ conversion into glucose, and the perchloric acid-soluble glycogen gave 83 and $85 \%$ conversion respectively. The enzyme digests were then heated to inactivate the amyloglucosidase, dialysed to remove the glucose, concentrated and then partially hydrolysed with $1 \mathrm{M}$-sulphuric acid at $100^{\circ} \mathrm{C}$ for $1 \mathrm{~h}$. The two hydrolysates both contained glucose and oligosaccharides having the chromatographic properties of gentiobiose, gentiotriose and gentiotetraose. These results show clearly that the glycogen preparations were contaminated with a significant amount of $\beta-(1 \rightarrow 6)$ glucan.

Fractionation procedures of the type devised by Trevelyan \& Harrison (1956) have been used in studies of the changes in carbohydrate composition that occur during the growth of yeasts (see, e.g., Trevelyan \& Harrison, 1956; Suomalainen \& Pfäffli, 1961; Chester \& Byrne, 1968). The present work shows that these results can now only have a semiquantitative significance, since they do not take into account the rate of synthesis of the $\beta-(1 \rightarrow 6)$ glucan. The existence of the latter was, of course, not known when the fractionation procedures were carried out.

We thank Ranks Hovis McDougall (Research) Ltd. for the award of a research grant (to R. B. E.), and Dr I. D. Fleming, Glaxo Research Ltd., for the purified amyloglucosidase.

Bacon, J. S. D. \& Farmer, V. C. (1968). Biochem. J. 110, $34 \mathrm{P}$.

Bacon, J. S. D., Farmer, V. C., Jones, D. \& Taylor, I. F. (1969). Biochem. J. 114, 557.

Chester, V. E. \& Byrne, M. J. (1968). Archs Biochem. Biophys. 127, 556.

Manners, D. J. (1957). Adv. Carbohyd. Chem. 12, 261.

Manners, D. J. \& Masson, A. J. (1969). FE BS Lett. 4, 122. Suomalainen, H. \& Pfäflli, S. (1961). J. Inst. Brew. 67, 247.

Trevelyan, W. E. \& Harrison, J. S. (1956). Biochem. J. 63, 23.

\section{The Gell and Exocellular Mannans from Hansenula holstii N.G.Y.C. 560}

By W. L. Cunningham and Gioconda San Blas. (Department of Brewing and Biological Sciences, Heriot-Watt University, Edinburgh EH1 $1 H X$, U.K.)

Mannose-containing polysaccharides have been isolated from the cell walls of most yeasts. These may occur as homoglycans or in combination with other monosaccharides, phosphate and protein. Certain species will also produce exocellular mannans that may be conveniently isolated from the culture media after removal of the cells. In 